\title{
RESENHA
}

\section{A política da Primeira República em "Coronelismo, enxada e voto", de Victor Nunes Leal}

Euclides Cesar ${ }^{1}$

Como citar: CESAR, Euclides. A política da Primeira República em "Coronelismo, enxada e voto”. Revista de Ciências do Estado. Belo Horizonte: v. 6, n. 1, e32492. ISSN: 2525-8036.

Resenha de LEAL, Victor Nunes. Coronelismo, enxada e voto: o município e o regime representativo no Brasil. 7. ed. São Paulo: Companhia das Letras, 2012.

Recebido em 13.03.2021

Aprovado em 19.05.2021

Publicado em 07.06.2021

\section{CONSIDERAÇÕES INICIAIS}

Victor Nunes Leal (1914-1985), ao escrever a sua tese para titulação na cátedra de Ciência Política na Faculdade Nacional de Filosofia da Universidade do Brasil (atual Universidade Federal do Rio de Janeiro), ainda com o nome "O município e o regime representativo no Brasil: contribuição ao estudo do coronelismo", defendida em 1947, possivelmente não tinha consciência do impacto da obra para a ciência política brasileira e para o estudo do período referente à Primeira República como um todo (1889-1930).

Publicada posteriormente sob o título "Coronelismo, enxada e voto - O município e o regime representativo no Brasil”, em 1948, trata-se de obra que, mesmo após setenta anos, permanece relevante ao explicitar a forma de ascensão política no Brasil (e as devidas repercussões sociais) nas primeiras décadas do século $\mathrm{XX}$, mecanismo que gerou raízes que, em alguma medida, permanecem até hoje na dinâmica política brasileira.

A ideia de confusão entre as esferas de atuação pública e privada no meio político brasileiro é difundida desde muito antes da publicação do livro ora resenhado; o que se deve

\footnotetext{
${ }^{1}$ Graduado em Direito pela Universidade Federal do Ceará em 2015. Antes, estagiou por dois anos na Justiça Federal do Estado do Ceará - $11^{\text {a }}$ Vara Federal (2013-2015). Atuou como advogado nos escritórios Cândido Albuquerque Advogados Associados (2015-2016) e RGM Advogados Associados (2016-2017). Atualmente, é Supervisor de Unidade Judiciária lotado na $13^{\text {a }}$ Vara Criminal de Fortaleza/CE. Aluno de Mestrado no Programa de Pós Graduação em Direito da Universidade Federal do Ceará (ingresso em 2020).
} 
ressaltar é a importância da abordagem e das conclusões de Victor Nunes Leal, que diferenciam sua obra de outras anteriormente publicadas.

José Murilo de Carvalho pontua, neste sentido, que Leal rompeu com as análises dicotômicas (feudalismo vs. capitalismo, casa-grande vs. Estado, litoral vs. Sertão, público vs. privado etc.), destacando a oposição, sobretudo, em relação a Nestor Duarte, a quem importava a separação rígida entre poder público e poder privado (CARVALHO, 2012, p. 9). Leal, por sua vez, o vínculo matricial entre as duas esferas, entrelaçando-as no sistema que desvela no decorrer do livro.

O presente trabalho não tem a pretensão de promover grandes debates a respeito da obra - muito embora não se possa deixar de lado a crítica necessária à análise do texto - ou mesmo de fazer um resumo de seus capítulos. A ideia condutora é a de apresentar alguns dos principais aspectos abordados pelo autor e como eles se encadeiam de modo a constituir um sistema capaz de se retroalimentar continuamente até a primeira ruptura promovida pela Revolução de 1930.

Importante ressaltar que a exposição dos conceitos presentes na obra "Coronelismo, enxada e voto" não significa que Victor Nunes Leal os tenha criado ou utilizado de forma primeva. É o caso das noções de mandonismo e clientelismo, ambas frequentemente confundidas com o próprio coronelismo. Como afirmou o próprio autor (LEAL, 1980, p. 13), tais noções são relevantes para sua obra apenas no que contribuem para a formação do complexo sistema de ascensão política da época e de dependência mútua entre os poderes público e privado:

Ora, não há uma palavra no meu livro pela qual se pudesse atribuir o status de senhor absoluto ao coronel, ou às expressões pessoais de mando do sistema coronelista, pois o que procurei examinar foi sobretudo o sistema. O coronel entrou na análise por ser parte do sistema, mas o que mais me preocupava era o sistema, a estrutura e a maneira pelas quais as relações de poder se desenvolviam na Primeira República, a partir do município.

Apesar da noção de sistema ser continuamente reforçada por Victor Nunes Leal, inevitável iniciar a presente análise por uma breve apresentação da peça-chave deste intrincado mecanismo. 


\section{PRELÚDIO: O CORONEL}

O "coronel" ascende como figura política relevante na esteira da antiga Guarda Nacional - órgão com funções de segurança pública e garantia da ordem municipal, sendo responsável por garantir o cumprimento de determinações judiciais e por fornecer destacamentos auxiliares ao Exército.

Leal destaca que o intuito do poder central ao criar a Guarda Nacional era, sobretudo, usar o poder privado em proveito do poder público: os oficiais da Guarda eram eleitos no seio da corporação, predominando a influência política local. A partir de 1850 a ascensão aos principais postos (dentre os quais, o de coronel) passou a depender de nomeação do governo central - e, assim, a ser utilizada como instrumento de cooptação política em virtude do prestígio do título. A barganha era direcionada às lideranças locais que, para além do domínio econômico, passavam também a ostentar o título de cunho paramilitar.

Basílio de Magalhães, em nota sobre a origem do termo "coronelismo", destaca que a população sertaneja estendeu o significado da palavra "coronel", passando a utilizá-la para designar "todo e qualquer chefe político, a todo e qualquer potentado". Mesmo após o declínio da Guarda Nacional, a partir da década de 1870, a figura dos coronéis e sua associação com os chefes políticos - que eram, ao mesmo tempo, "os mais opulentos fazendeiros ou o comerciante e industriais mais abastados" - permaneceram no imaginário popular, resistindo à mudança do Império para a República.

A histórica incapacidade do poder público de chegar de forma organizada nos municípios fornecia amplo espaço de atuação para o poder privado. Assim, os coronéis exerciam um poder com poucas limitações - geralmente impostas por coronéis adversários, quando existiam. Não obstante, o "coronelismo", do ponto de vista do autor, não decorre da força dos "coronéis", mas sim de sua progressiva fraqueza. É o que será demonstrado nos tópicos a seguir.

\section{O SISTEMA CORONELISTA}

Como visto, Victor Nunes Leal não via o coronelismo como um fenômeno concentrado na figura do coronel. Pelo contrário: o coronel representava apenas a ponta de um longo fio que partia das disputas municipais, emaranhava-se no poder estadual e sustentava o poder federal.

O autor afirma, já no início de "Coronelismo...", que se trata de uma "superposição de formas desenvolvidas do regime representativo a uma estrutura econômica e social 
inadequada" (LEAL, 2012, p. 35). Em outras palavras, o regime representativo - constituído por indivíduos eleitos para exercerem cargos públicos nos âmbitos federal e estadual, sobretudo - se articulava de forma débil com a estrutura social brasileira da época, ainda profundamente vinculada às suas raízes rurais.

No decorrer dos capítulos, Nunes Leal sustentará que o nascedouro desse sistema desencaixado estará na dificuldade encontrada pela Coroa Portuguesa em controlar a sua colônia sul-americana, haja vista a sua extensão territorial e a fragilidade do poder público português. Assim sendo, era útil para Portugal a grande autoridade que exerciam os senhores de terra sobre os territórios que ficavam sob sua tutela - estimulando, assim, o mandonismo local a fim de proteger a ocupação do território.

Ocorre, porém, que a superveniência do fortalecimento do poder público - sobretudo após a chegada da Corte Real ao Brasil, mas com manifestações anteriores, como os juízes de fora - foi minando, ainda que aos poucos, o elevado poder dos grandes latifundiários. $\mathrm{O}$ processo se intensificou com a Independência e, após o período regencial, consolidou-se um sistema de poder estatal centralizado, que dava pouca margem de atuação às municipalidades.

A concessão de pequena margem de ação às autoridades públicas locais é central para a fluidez do sistema coronelista. Por mais que crescesse o poder público no Brasil - no período Imperial ainda sob um modelo centralizado e, posteriormente, já sob regime republicano, com maior autonomia aos entes estaduais - os municípios foram deixados de fora deste processo. Assim, ainda que houvesse autoridades constituídas, a estas escapava a autonomia - seja por limitações orçamentárias, seja por limitações de natureza puramente política, uma vez que a definição do "peculiar interesse" dos municípios (previsto no art. 68 da Constituição brasileira de 1891) era de competência das legislaturas estaduais.

A importância política do "coronel" nascia justamente dessa fragilidade: atadas as mãos das autoridades locais, cabia ao "coronel", detentor de condições econômicas relativamente favoráveis e de certa influência política, pressionar o poder público estadual para a construção de estradas, pontes, clubes, hospitais, telégrafos, entre outras, de modo a ser visto como o verdadeiro responsável pelas pequenas melhorias nas condições de vida da população que vivia em seu entorno.

Essa "fidelização" era reforçada pelo fato de que, sendo grande proprietário de terras, ao "coronel" era devida a renda e o abastecimento de um significativo contingente populacional. Desta forma, estavam dadas as condições para que direcionasse os votos daqueles que dependiam de si para os candidatos de seu interesse - os governistas. 


\section{A DECADÊNCIA DO CORONEL}

A necessidade de apoio do governo aos "coronéis" para o funcionamento do sistema não é uma demonstração de força dos grandes senhores de terra, mas de sua fraqueza. Nunes Leal não desenha o "coronel” como uma figura forte, autoritária, plenipotenciária, pelo contrário: durante a Primeira República, o "coronel” foi apenas um espectro do homem forte que fora outrora.

É por isso que a adesão ao governo é mecanismo fundamental para o sucesso do “coronel” enquanto ator político. Suas realizações dependerão do apoio do poder público; sendo assim, natural que os diversos "coronéis" disputem menos o apoio popular do que o apoio dos candidatos situacionistas.

Esta posição é vinculada à predominância do cenário rural sobre o urbano no contexto social da época. Na verdade, pode-se dizer que o ruralismo da Primeira República é herdeiro do modo de colonização empregado por Portugal e da manutenção das estruturas produtivas sob a tutela do Império. A proclamação da República, muito embora tenha reforçado o poder público - o qual passou a ser dotado de um maior grau de legitimidade (ainda que com óbvias ressalvas) -, não dilapidou tal estrutura, mas, ao reverso, esforçou-se para protegê-la.

Ocorre que o avanço das estruturas urbanas vinha a reboque do próprio sucesso do sistema de produção rural. O vínculo do setor produtivo-exportador - voltando para a exportação de produtos primários - com o mercado internacional impulsionou a dinamização da estrutura local, ainda que a passos lentos. Esta dinamização permitiu o desenvolvimento de sistemas de produção voltados para o mercado interno, o que, por sua vez, fez nascerem novas categorias sociais ligadas ao meio urbano, como assevera Cardoso (1970, pp. 60-61):

\footnotetext{
Assim, ao aparecerem os primeiros esforços para um mercado interno, surgem ou se desenvolvem nas cidades novos grupos sociais: artesãos, pequenos comerciantes, profissionais, setores vinculados aos serviços (transportes, bancos, educação, serviços públicos etc.). Em função desse mercado constituem-se os primeiros núcleos industriais, e formam-se, em consequência, tanto uma burguesia urbana como setores operário-populares; assim, em um primeiro momento os grupos sociais urbano-industriais formam-se em consequência da expansão do setor exportador e sem que seus interesses econômicos oponham-se aos deste setor, mas, pelo contrário, tomam-se um setor complementar daquele.
}

O período da Primeira República representa o início da fase de transição entre um país cuja economia é baseada na exportação de produtos agrícolas para um novo equilíbrio no qual a indústria representasse papel central no desenvolvimento econômico. Se o desenvolvimento da indústria implica na ascensão de classes urbanas, reduz-se o contingente 
populacional submetido à esfera de influência do "coronel" e, assim, sua capacidade de controlar os resultados eleitorais das suas subscrições territoriais.

Isto não quer dizer, para Leal, que o poder dos "coronéis" será extirpado de todo, mas sim que o coronelismo, enquanto sistema retroalimentado de acomodação entre o poder público e privado, não pode existir quando o cenário rural deixar de ser predominante em relação ao urbano.

\section{A TROCA DE FAVORES}

Como visto, o coronelismo (enquanto sistema) existiu em um contexto que os grandes proprietários de terra aliavam-se às autoridades públicas, especialmente as estaduais, promovendo um ciclo de troca de favores que mantinha o esquema operando por si mesmo.

Neste ponto, é oportuno recordar que a Constituição de 1891 adotou um modelo de federalismo dual, inspirado no modelo clássico estadunidense. Neste modelo, as competências destinadas à União são enumeradas expressamente, cabendo aos Estados-membros o exercício das funções residuais. Aos Estados também competia definir qual o âmbito de atuação dos municípios (cf. art. 68 da Constituição de 1891) - uma limitação que, como visto acima, interessava tanto às oligarquias estaduais quanto aos "coronéis".

Dentro desse enlace entre o poder público e o poder privado, aos "coronéis" cabia fornecer a "mão de obra" para funcionamento da estrutura: os eleitores. Nunes Leal (2012, p. 48) afirma que:

\footnotetext{
A maioria do eleitorado brasileiro reside e vota nos municípios do interior. E no interior o elemento rural predomina sobre o urbano. Esse elemento rural, como já notamos, é paupérrimo. São, pois, os fazendeiros e chefes locais que custeiam as despesas do alistamento e da eleição. Sem dinheiro e sem interesse direto, o roceiro não faria o menor sacrifício nesse sentido.
}

Os chefes locais, portanto, sustentavam financeiramente o funcionamento do regime democrático no Brasil na Primeira República. Não sendo o voto obrigatório (cf. art. 70 da Constituição de 1891) e dependendo o alistamento eleitoral da vontade do próprio eleitor, todo o esforço para construir o contingente eleitoral que levaria ao poder as oligarquias caberia ao "coronel".

As três principais atribuições do poder público no funcionamento do mecanismo coronelista eram (a) a indicação de cargos políticos, (b) o uso das forças de segurança para perseguir os opositores dos "coronéis" aliados ao governo e (c) a promoção de benfeitorias nas regiões de influência dos "coronéis". 
Na política da Primeira República, a instância superior dependia substancialmente da instância inferior; assim, os cargos públicos colocados à disposição dos poderes federais eram preenchidos a depender da manifestação dos poderes estaduais - a qual, por sua vez, era fortemente influenciada pelos "coronéis", que tinham, assim, a possibilidade de indicar alguns dos integrantes das burocracias das esferas superiores.

Mas não só: o que era de ainda mais interesse para os "coronéis" eram os cargos mais próximos - que possibilitavam concretizar o domínio que o chefe local tinha na região. Esta influência inclui as forças de segurança, atores-chave para o compromisso coronelista.

Destaca Nunes Leal que a própria nomeação dos delegados e subdelegados de polícia ficará a cargo dos "coronéis", o que põe a polícia "a serviço" do chefe local dominante - cuja perseguição aos rivais passará incólume pelas vistas grossas dos governos estaduais. A soma da perseguição com a cegueira deliberada das autoridades estaduais tornará dificultosa a vida de um "coronel" oposicionista, o que explica a disputa dos coronéis pela preferência do grupo político de situação.

O terceiro elemento é o mais crucial para a perpetuação do ciclo coronelista. A capacidade deficiente do município gerava enorme dependência do poder estadual que, obviamente, dada a limitação dos recursos disponíveis, privilegiaria os municípios onde contou com o apoio do chefe local. Promovia-se, assim, a prestação de serviços públicos de primeira necessidade para a população, elevando o prestígio não só do governo, mas, principalmente, do próprio "coronel".

Esse prestígio, somado aos esforços do "coronel” para alistamento eleitoral, fidelizará os eleitores - que elegerão o candidato indicado pelo "coronel” e, assim, manterão o mecanismo em pleno funcionamento.

\section{MANDONISMO E CLIENTELISMO}

Evidentemente, não se pode falar em coronelismo sem falar em mandonismo e clientelismo. Já vimos o esforço que fez Nunes Leal para que sua concepção de coronelismo, cuja característica marcante está no aspecto sistemático da política desenvolvida nas primeiras décadas no século XX, não fosse confundida com o mandonismo, muito embora este fosse um elemento presente em sua análise.

Para Leal, o mandonismo "se manifesta na perseguição aos adversários: 'para os amigos pão, para os inimigos pau"' (LEAL, 2012, p. 51). Trata-se de uma característica que o coronelismo herdou da sociedade colonial, época em que os senhores rurais acumulavam 
tanto poder que chegavam a ir de encontro às normas régias - as quais vinham, supervenientemente, a sancionar as condutas que iam contra suas próprias disposições.

José Murilo de Carvalho (1997) se atém a esse conceito de forma mais específica:

\begin{abstract}
Este talvez seja o conceito que mais se aproxime do de caciquismo na literatura hispano-americana. Refere-se à existência local de estruturas oligárquicas e personalizadas de poder. O mandão, o potentado, o chefe, ou mesmo o coronel como indivíduo é aquele que, em função do controle de algum recurso estratégico, em geral a posse da terra, exerce sobre a população um domínio pessoal e arbitrário que a impede de ter livre acesso ao mercado e à sociedade política. $\mathrm{O}$ mandonismo não é um sistema, é uma característica da política tradicional. Existe desde o início da colonização e sobrevive ainda hoje em regiões isoladas.
\end{abstract}

Se por mandonismo entendermos, em uma simplificação, a autoridade superior do senhor de terras (entenda-se: o grande proprietário rural, latifundiário) no interior de sua propriedade e na região de sua influência, é evidente que não há espaço para separá-lo da noção de coronelismo empregada por Nunes Leal. Por outro lado, trata-se de conceito insuficiente para abarcar a dinâmica coronelista que envolvia até mesmo a escolha do chefe do Poder Executivo Federal.

Já o clientelismo, enquanto conceito, aparece de forma difusa no texto do jurista mineiro. Carvalho assim o define: "tipo de relação entre atores políticos que envolve concessão de benefícios públicos, na forma de empregos, benefícios fiscais, isenções, em troca de apoio político, sobretudo na forma de voto" (CARVALHO, 1997). É certo que o compromisso "coronelista" envolve compromissos que também podem ser definidos como “clientelistas". Novamente, porém, não se pode confundir o alcance de ambos os conceitos.

O coronelismo proposto por Nunes Leal explica uma sistemática que fundamentação do poder político em um determinado espaço de tempo (Primeira República), com uma série de fatores que a condicionam, conforme visto anteriormente. $\mathrm{O}$ clientelismo proposto por Carvalho (costumeiramente associado à ideia de coronelismo) está presente em diversos momentos da política brasileira e estrangeiro, prescindindo, inclusive, daquele que é o locus do coronelismo: o meio rural de um país pré-industrializado.

\title{
CONSIDERAÇÕES FINAIS
}

Como já anunciado, o presente trabalho não tem a pretensão de tecer uma crítica à obra d-e Victor Nunes Leal ou a de apresentar o dissenso em torno dos conceitos que o autor utilizara ou da forma como sistematizou o sistema coronelista, mas a de apresentar noções que facilitarão a compreensão do sistema descrito pelo autor. 
Isto não significa que as ideias apresentadas no livro não foram objeto de intensa discussão e até mesmo de contestação.

No livro Coronelismo e Oligarquias (1889-1934): a Bahia na Primeira República brasileira, Eul-Soo Pang formula outro conceito de coronelismo, o qual se expande para além dos donos de terras, incluindo "comerciantes, advogados, médicos, burocratas, professores, industriais e até mesmo padres", chegando a afirmar que "os padrões de distribuição de terras têm muito pouca relação com a estrutura e o funcionamento do coronelismo" (PANG, 1979, pp. 20 e 47). Raymundo Faoro diminui o componente de classe visto em Coronelismo, enxada e voto ao afirmar que a origem do poder dos coronéis "deriva do prestígio, da honra social, tradicionalmente reconhecido. Não se confunde, ao contrário da crença corrente, com modalidade ou derivação do domínio patriarcal” (FAORO, 2001, p. 755). Janotti, por sua vez, quando afirma que "o poder privado que, como visto, era desmesurado na Colônia, continuou a sê-lo durante o Império e a República", interpreta o coronelismo como uma mera sequência do domínio do poder privado sobre o poder público no Brasil (JANOTTI, 1981, p. 39), indo em sentido contrário à tese de Leal de que se trataria, na verdade, de fenômeno ligado à progressiva perda de poder por parte dos "coronéis".

Partindo para uma análise mais profunda do fenômeno coronelista, Maria Isaura Pereira Queiroz assevera que analisar apenas o aspecto político do coronelismo significa "mutilar um conjunto complexo, empobrecendo-o e não permitindo uma compreensão mais ampla, tanto em si mesmo quanto em sua evolução histórico-social e política" (QUEIROZ, 1994, p. 174). Esta abordagem vê o coronelismo como um mecanismo ainda mais complexo, com subsistemas dentro de si, a depender do contexto fático (pluralidade ou singularidade de coronéis; existência de cabos eleitorais; porte dos coronéis; comportamento do eleitor etc). Além de político, trata-se de fenômeno social que tem como núcleo as chamadas "parentelas", agrupamento rural de natureza familiar, chefiado pelo coronel, que decidia seu sucessor (o título não era, necessariamente, transmitido de forma hereditária).

O certo é que muitas outras vozes dissonantes se fizeram ouvir ao longo das sete décadas que se sucederam após a publicação de Coronelismo, enxada e voto. A advertência se faz necessária para que o leitor deste trabalho não confira à obra de Nunes Leal o status de dogma que o próprio autor jamais ousou atribuí-la. Até hoje, porém, é instrumento de primeira hora para os que pretendem entender o funcionamento da política brasileira nos primórdios da República. 
Neste trabalho, foram selecionados três aspectos que não podem passar despercebidos pelo leitor: a decadência do poder do "coronel" como constituinte do "coronelismo", a intensa troca de favores entre poderes público e privado funcionando como engrenagens de um grande sistema e a diferenciação entre mandonismo, clientelismo e coronelismo - feita implicitamente pelo próprio autor em sua obra e aprofundada posteriormente, sobretudo por José Murilo de Carvalho.

Estas ideias, além de presentes em todo o texto de Coronelismo, enxada e voto, são fundamentais para se entender o reflexo do coronelismo da Primeira República na construção das estruturas políticas posteriores - não apenas no período varguista, mas também (e, por que não, principalmente) na democracia brasileira contemporânea.

\section{REFERÊNCIAS BIBLIOGRÁFICAS}

BRASIL. Constituição da República dos Estados Unidos do Brasil, de 24 de fevereiro de 1891. Disponível em: <http://www.planalto.gov.br/ccivil_03/con stituicao/constituicao91.htm>. Acesso em: 15 de novembro de 2020.

CARDOSO, Fernando Henrique; FALLETO, Enzo. Dependência e desenvolvimento na América Latina. Rio de Janeiro: Zahar, 1970, pp. 60-61.

CARVALHO, José Murilo de. Mandonismo, Coronelismo, Clientelismo: Uma Discussão Conceitual. Dados, Rio de Janeiro, v. 40, n. 2, 1997. Disponível em <https://doi.org/10.1590/S001152581997000200003>.

Acesso em 15 nov. 2020.

CARVALHO, José Murilo de. Prefácio à sétima edição. In: LEAL, Victor Nunes. Coronelismo, enxada e voto: o município e o regime representativo no Brasil. 7. ed. São Paulo: Companhia das Letras, 2012, pp. 6-15.

FAORO, Raymundo. Os donos do poderformação do patronato político brasileiro. 3. ed. rev. Porto Alegre: Globo Livros, 2001.

JANOTTI, Maria de Lourdes Monaco. O coronelismo: uma política de compromissos. 2. ed. São Paulo: Editora Brasiliense, 1981.

LEAL, Victor Nunes. Coronelismo, enxada e voto: o município e o regime representativo no Brasil. 7. ed. São Paulo: Companhia das Letras, 2012.

LEAL, Victor Nunes. O coronelismo e o coronelismo de cada um. Dados, v. 23, n. 1, p. 11-14, 1980.

PANG, Eul-Soo. Coronelismo e oligarquias, 1889-1934: a Bahia na Primeira República brasileira. Rio de Janeiro: Civilização Brasileira, 1979.

QUEIROZ, Maria Isaura Pereira. O coronelismo numa interpretação sociológica. In: FAUSTO, Boris. História Geral da Civilização Brasileira. Tomo III (O Brasil Republicano: economia e cultura). Rio de Janeiro: Bertrand Brasil, 1994, pp. 172-212. 
THE FIRST REPUBLIC POLITICS IN VICTOR NUNES LEAL'S “CORONELISMO, ENXADA E VOTO"

Euclides Cesar

How to cite this article: CESAR, Euclides. A política da Primeira República em "Coronelismo, enxada e voto". Revista de Ciências do Estado. Belo Horizonte: v. 6, n. 1, e32492. ISSN: 2525-8036. 